\title{
Peran Manajerial Kepala Sekolah Dalam Meningkatkan Mutu Pendidikan di Sekolah Dasar
}

\author{
Naraya Fitri Anjani1 ${ }^{*}$, Febrina Dafit² \\ 1,2 Jurusan Pendidikan Guru Sekolah Dasar, Universitas Pendidikan Islam Riau, Pekanbaru, Indonesia
}

\section{A R T I C L E I N F O}

Article history:

Received August 09, 2021

Revised August 15, 2021

Accepted September 30, 2021

Available online October 25, 2021

Kata Kunci:

Manajerial Kepala Sekolah, Mutu Pendidikan

Keywords:

Principal Managerial, Quality Of Education

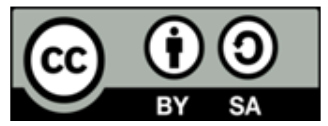

This is an open access article under the CC BY-SA license.

Copyright $(\subset 2021$ by Author. Published by Universitas Pendidikan Ganesha.

\begin{abstract}
A B S T R A K
Penelitian ini bertujuan untuk: menganalisis peran manajerial kepala sekolah dalam meningkatkan mutu pendidikan di Sekolah dasar. Penelitian in menggunakan metode pendekatan kualitatif. Subjek penelitiannya adalah kepala sekolah dan guru. Metode pengumpulan data menggunakan wawancara, obeservasi, dan dokumentas. Teknik analisis data menggunakan analisis data kualitatif dari Miles dan Huberman Hasil penelitian ini menjelaskan kepala sekolah sebagai manajer memiliki peran membuat struktur organisasi dan mengajak orangtua murid dengan program komite sekolah dan melengkapi supras yang dibutuhkan; merancang program dengan menguraikan kebutuhan pendidik dan tenaga pendidik yang menjalankan tugas, merancang kurikulum yang dijalankan; mengawasi output, proses belajar mengajar, dan peserta didik mulai dari penerimaan siswa hingga selesai; menunjukkan contoh yang baik dan tenang dalam bekerja, memberikan motivasi serta penghatgaan kepada personilnya baik dari segi motil maupun materil, mengikutsertakan pendidik dan tenaga pendidik dalam diklat diklat serta memotivasi guru guru senior supaya memiliki semangat life long education; adapun hambatan yang dihadapi adalah kurangnya sarana dan prasarana dalam proses belajar mengajar, masih ada pendidik dan tenaga pendidik yang tidak disiplin, dan kurangnya komunikasi kepala sekolah dengan beberapa pendidik dan tenaga pendidik. Manajerial kepala sekolah yang baik akan menghasilkan mutu pendidikan yang baik juga yang tentunya akan mempengaruhi hasil belajar dan prestasi sekolah. Hasil penelitian ini diperoleh bahwa masih dibutuhkan sebuah program untuk meningkatkan mutu pendidikan baik berkaitan dengan pembelajaran maupun tidak.
\end{abstract}

\section{A B S T R A C T}

This study aims to: analyze the managerial role of school principals in improving the quality of education in elementary schools. This study uses a qualitative approach. The research subjects are principals and teachers. Methods of data collection using interviews, observation, and documentation. The data analysis technique uses qualitative data analysis from Miles and Huberman. The results of this study explain that the principal as a manager has the role of creating an organizational structure and inviting parents of students to the school committee program and completing the necessary supras; designing programs by outlining the needs of educators and teaching staff who carry out their duties, designing the curriculum that is implemented; supervising the output, teaching and learning process, and students from admission to completion; show a good and calm example at work, provide motivation and appreciation to its personnel both in terms of motile and material, involve educators and educators in training and education and motivate senior teachers to have the spirit of life long education; The obstacles faced are the lack of facilities and infrastructure in the teaching and learning process, there are still undisciplined educators and teaching staff, and the lack of communication between the principal and several educators and teaching staff. A good managerial principal will produce a good quality of education as well which of course will affect learning outcomes and school achievement. The results of this study indicate that a program is still needed to improve the quality of education, whether related to learning or not.

\section{PENDAHULUAN}

Keberhasilan sebuah sekolah tidak terlepas dari kepemimpinan kepala sekolah. Kepemimpinan kepala sekolah dianggap memainkan peran penting dalam efektivitas dan peningkatan sekolah (Zheng et al., 2017). Proses pendidikan di sekolah sangat tergantung pada pelaku utama yang sangat penting yaitu kepala sekolah dan guru (Juniarti et al., 2019; S et al., 2018). Kepala sekolah adalah seorang tenaga fungsional guru yang 
diberikan tugas untuk memimpin suatu sekolah dimana diselenggarakannya proses belajar mengajar atau tempat dimana terjadi interaksi antara guru yang memberikan pelajaran dan murid yang menerima pelajaran (Kastawi, 2021; Kurniady et al., 2018). Banyak penelitian yang sudah dilakukan berkaitan dengan manajerial kepala sekolah yang menyatakan bahwa manajerial kepala sekolah memberikan pengaruh terhadap mutu pendidikan, peningkatan mutu pendidikan disebabkan oleh kepuasan atas kepemimpinan kepala sekolah serta staf sekolah (Masrukhin, 2018; Oktarina \& Rahmi, 2019). Kepemimpinan kepala sekolah yang berkualitas akan mempengaruhi presatsi siswa (Grissom et al., 2015; Hastuti, 2017). Terjadinya perubahan kepemimpinan kepala sekolah akan mempengaruhi prestasi belajar siswa (Rismawan, 2015; Wills, 2016). Jabaran-jabaran tersebut memberikan gambaran terkait peran manajerial kepala sekolah dalam meningkatkan mutu pendidikan. Manajerial kepala sekolah yang berkualitas baik akan berdampak terhadap kualitas mutu pendidikan. Untuk tercapainya hal tersebut tentunya kepala sekolah harus mempunyai kompetensi, sikap serta keterampilan.

Keterampilan manajerial kepala sekolah merupakan hal yang penting untuk meningkatkan mutu pendidikan sekolah (Masrukhin, 2018). Keterampilan manajerial didasarkan pada tipe dari keterampilan yang dibutuhkan untuk menunjukkan kinerja kepala sekolah (Santiari, 2020; Sukayana et al., 2019). Keterampilan ini biasanya mencakup mengorganisasikan, merencanakan, memonitor, memimpin yang termasuk kedalam tiga kategori yang sangat penting terutama kepala sekolah akan menunjukkan fungsinya dan aturan yang memadai seperti: kemampuan konseptual, hubungan manusia, dan kemampuan teknis (Norma Puspitasari, 2015; Taswir, 2014). Keterampilan manajerial kepala sekolah sangat penting dalam mesukseskan kondisi pendidikan karena pedoman utama guru guru dalam melaksanakan proses belajar mengajar bergantung pada kepala sekolah atau kebijakan kepala sekolah serta tindakan kepala sekolah (Hastowo \& Abduh, 2021; Masrukhin, 2018). Maka dari itu kemampuan manajerial kepala sekolah hendaknya menjalankan aktifitas manajemen yang dijalankan kepala sekolah secara prosedural guna memberdayakan semua sumber daya yang tersedia untuk mencapai tujuan organisasi secara efektif dan efisien.

Namun yang terjadi dilapangan untuk mewujudkan satuan pendidikan yang bermutu tidaklah mudah. Berbagai macam upaya telah dilakukan untuk meningkatkan mutu pendidikan melalui pendidikan yang efektif belum mencapai hasil yang optimal (Masrukhin, 2018). Hal ini terutama sekali dialami oleh para kepala sekolah di daerah-daerah terpencil (Taswir, 2014). Para kepala sekolah umumnya melakukan pengelolaan sekolah berdasarkan pada pengalaman pribadi sesuai dengan konsep pemikiran yang dimilikinya. Permasalahan tersebut juga terjadi di SDN 4 Bathin Solapan Kabupaten Bengkalis. Kepala sekolah menghadapi berbagai masalah yang ada diantaranya adalah masih adanya pendidik dan tenaga pendidik yang kurang disiplin, kurangnya komunikasi kepala sekolah dengan pendidik dan tenaga pendidik. Seain itu masalah sarana dan prasarana juga dihadapi oleh sekolah sehingga dalam proses belajar mengajar kurang efektif. Dan masih ada beberapa masalah lain yang dihadapi kepala sekolah di SDN 4 Bathin Solapan Kabupaten Bengkalis. Jika permasalahan tersebut dibiarkan akan memberikan dampak buruk terhadap mutu pendidikan. Oleh sebab itu yang bisa digunukan sebagai tolak ukur kepala sekolah dalam memimpin sekolah adalah meningkatnya mutu pendidikan.

Mutu pendidikan sendiri sering diartikan sebagai karakteristik pendidikan yang sesuai dengan kriteria tertentu yang dapat memenuhi kepuasan pengguna pendidikan yaitu peserta didik, orangtua, serta pihak pihak lainnya (Azhari \& Kurniady, 2016; Margareta \& Ismanto, 2017). Mutu pendidikan akan tercapai jika didukung oleh komponen dalam pendidikan yang terorganisasikan dengan baik (Fauzi \& Falah, 2020; Kurniawati et al., 2020). Maka dari itu kepala sekolah dan guru dituntut untuk bertanggung jawab terhadap kualitas proses serta hasil belajar guna meningkatkan mutu pendidikan. Beberapa hal yang jadi penentu terwujudnya proses pendidikan yang bermutu, antara lain: keefektifan gaya kepemimpinan kepala sekolah; partisipasi aktif dan rasa tanggung jawab guru dan staff; keberlangsungan proses belajar mengajar yang efektif; kurikulum yang relavan; memiliki visi dan misi yang terarah; iklim sekolah yang kondusif; g) keterlibatan orangtua dan masyarakat instrinsik.. Upaya meningkatkan mutu pendidikan adalah usaha yang harus dilakukan atau diupayakan secara terus menerus agar dapat mencapai harapan untuk pendidikan yang berkualitas dan relavan. Mutu pendidikan bukan hanya terfokus pada faktor input pendidikan, namun lebih memperlihatkan pada faktor dalam proses pendidikan, namun lebih memperlihatkan pada faktor dalam proses pendidikan. Input pendidikan merupakan suatu hal yang mutlak tapi menjamin secara otomatis meningkatkan mutu Pendidikan. Hal ini menjadi salah satu alasan penelitian yang bertujuan mengenalisis peran manajerial kepala sekolah dalam meningkatkan mutu pendidikan. Mengetahui kondisi manajerial kepala sekolah akan memberikan gambaran bagaimana upaya yang perlu dilakukan dalam meningkatkan mutu pendidikan. Gambaran yang jelas tentang bagaimana manajerial kepala sekolah dalam merancang, meorganisai, megarahkan dan mengkordinasikan staf akan menjadi dasar yang bisa digunakan untuk meningkatkan mutu pendidikan. Penelitian tentang peran manajerial kepala sekolah dalam meningkatkan mutu pendidikan sudah banyak dilakukan. Dari hasil penelitian tersebut diperoleh bahwa manajerial kepala sekolah dapat meningkatkan mutu Pendidikan (Hastowo \& Abduh, 2021; Kurniawati et al., 2020; Masrukhin, 2018). Jadi sangat penting dilakukan penelitian untuk menganalisis peran manajerial kepala sekolah dalam meningkatkan mutu pendidikan. 


\section{METODE}

Desain penelitian ini adalah penelitian deskriptif kualitatif. Penelitian kualitatif deskriptif adalah penelitian yang menghasilkan penemuan yang tidak dapat dicapai menggunakan prosedur statistic ataupun kautitatif (Sidiq \& Choiri, 2019). Penelitian ini memfokuskan pada bagaimana peran manajerial kepala sekolah dalam meningkatkan mutu pendididkan di SDN 4 Bathin Solapan Kabupaten Bengkalis. Penelitian kualitatif ini lebih menekankan pada deskripsi atau menggambarkan pada fenomena yang ada, baik fenomena yang bersifat ilmiah maupun rekayasa manusia. Penelitian ini menkaji bentuk aktivitas, karakteristik, perubahan, hubungan, kesamaan dan perbdeaan dengan fenomena lain. Menurut Nuralita (2020:4) dalam penelitian kualitatif peneliti hadir secara langsung ke lapangan agar memperoleh data secara akurat. Subjek penelitian ini adalah SDN 4 Bathin Solapan Kabupaten Bengkalis yang beralamat di Jl. Sakobotik, Km 16, Desa Boncah Mahang, Kecamata Bathin Solapan, Kabupaten Bengkalis. Alur dalam penelitian ini dimulai dari mengemukakan permasalahan yaitu kurang efektifnya manajerial kepala sekolah sehingga banyak terjadinya masalah yang berpengaruh terhadap mutu pendidikan. Kemudian peneliti menentukan judul yaitu "Peran Manajerial Kepala Sekolah Dalam Meningkatkan Mutu Pendidikan Di SDN 4 Bathin Solapan Kabupaten Bengkalis". Kemudian dilanjutkan dengan focus di daam penelitian berjumlah dua yaitu 1) bagaimana peran manajerial dalam meningkatkan mutu pendidikan di SDN 4 Bathin Solapan 2) Bagaimana hambatan-hambatan yang dihadapi kepala sekolah dalam meningkatkan mutu pendidikan di SDN 4 Bathin Solapan.

Metode pengumpulan data menggunakan wawancara, obeservasi, dan dokumentasi. Sumber data diperoleh dari kepala sekolah SDN 4 Bathin Solapan, dan guru. Kepala sekolah dan guru merupakan sumber data dimana kepala sekolah dan guru SDN 4 Bathin Solapan memiliki kesempatan yang sama untuk menjadi sumber data pada penelitian ini. Penelitian ini menggunakan kombinasi wawancara terstruktur dan wawancara tidak terstruktur dimana untuk mengetahui peran manajerial kepala sekolah dalam meningkatkan mutu pendidikan di SDN 4 Bathin Solapan dan mengetahui apa saja hambatan yang dihadapi kepala sekolah dalam meningkatkan mutu pendidikan di SDN 4 Bathin Solapan. Serta memeperkuat hasil observasi pelaksanaan manajerial kepala sekolah dalam meningkatkan mutu pendidikan di SDN 4 Bathin Solapan. Penelitian ini menggunakan teknik penelitian observasi untuk memperoleh data bagaimana pelaksanaan manajerial kepaa sekolah di SDN 4 Bathin Solapan Kabupaten Bengkalis. Observasi ini menggunakan pengamatan biasa. Gunawan (2017) pengamatan biasa mengharuskan peneliti untuk tidak ikut dalam emosi pelaku yang menjadi sasaran penelitiannya. Penelitian ini mengamati pelaksanaan manajerial kepala sekolah di SDN 4 Bathin Solapan Kabupaten Bengkalis. Dalam penelitian ini, dokumentasi yang digunakan berupa dokumentasi tertulis pada buku perencanaan manajerial kepala sekolah dan gambar gambar pelaksanaan dalam program manajerial kepala sekolah dan kegiatan wawancara serta observasi. Penelitian ini menggunakan teknik analsiis dari Miles dan Huberman yang digambarkan dalam (Sugiyono, 2017), yang terdiri atas 1) Data Collection / Pengumpulan Data; 2) Data Reduction (Reduksi Data); 3) Data Display (Penyajian Data); dan 4) Conclusion drawing/verification.

\section{HASIL DAN PEMBAHASAN}

\section{Hasil}

Hasil penelitian yang bertujuan menganalisis peran manajerial dalam meningkatkan mutu pendidikan di SDN 4 Bathin Solapan Kabupaten Bengkalis. Pertama, kompetensi manajerial kepala sekolah menjadi faktor yang dominan dalam proses meningkatkan mutu pendidikan di sekolah. Selain itu, pelaksanaan proses manajerial mulai dari perencanaan, pengorganisasian, hingga monitoring yang dilakukan untuk meningkatkan mutu pendidikan di SDN 4 Bathin Solapan ialah tindakan dan kebijakan yang harus dilakukan kepala sekolah secara adil dan bijaksana dalam mengarahkan dan membantu tenaga pendidik untuk meningkatkan mutu pendidikan di sekolah. Inovasi juga perlu dilakukan untuk SDN 4 Bathin Solapan agar semakin berkembang, dalam hal ini kepala sekolah, guru, serta komite bekerja keras untuk meningkatkan mutu pendidikan di sekolah, sekolah yang terakreditasi B telah berusaha menjadi terakreditasi A. perlunya sarana untuk menunjang atau mendukung proses belajar mengajar siswa dan program program sekolah lainnya agar lebih optimal dan efisien. Kepemimpinan kepala sekolah berhasil apabila mereka memahami keberadaan sekolah sebagai organisasi yang kompleks dan unik, serta mampu melaksanakan peranan kepala sekolah sebagai seseorang yang diberi tanggungjawab untuk memimpin sekolah (Juniarti et al., 2019; Setiyati, 2016). Selain itu, kepemimpinan kepala sekolah yang mau bekerjasama merupakan jenis kepemimpinan yang memberikan kontribusi untuk meningkatkan mutu pendidikan (Fadhli, 2017).

Dalam melaksanakan tugas kependidikannya, sekolah SDN 4 Bathin Solapan Kabupaten Bengkalis tertuju pada visi dan misi yang sudah tertanam sejak SDN 4 Bathin Solapan didirikannya SDN 4 Bathin Solapan Kabupaten Bengkalis. Visi SDN 4 Bathin Solapan Kabupaten Bengkalis ialah "Menjadikan Sekolah yang Berwawasan IPTEK dengan berlandaskan IPTAQ". Visi ini selalu dijadikan sebagai pedoman dan pondasi awal untuk SDN 4 Bathin Solapan Kabupaten Bengkalis dalam melangkah. Baik dalam menentukan program sekolah maupun melaksanakan program, memilih program, guna menjadikan sekolag agar lebih baik. Adapun misi yang dipegang oleh SDN 4 Bathin Solapan Kabupaten Bengkalis membentuk siswa agar menjadi manusia yang 
berpengetahuan, percaya diri serta berakhlak mulia. Misi ini dijabarkan ke dalam 3 point yaitu: mengoptimalkan proses pembelajaran dan bimbingan, mengembangkan pengetahuan bidang IPTEK (Bahasa, Matematika, Kesenian, dan Komputer), dan menanamkan keyakinan melalui pengalaman ajaran agama. Berdirinya SDN 4 Bathin Solapan Kabupaten Bengkalis tidak terlepas dari tujuan tujuan khusus. Pastinya untuk mempersiapkan siswa agar menjadi percaya diri, berpengetahuan, dan berakhlak mulia. Tujuan yang diharapkan dapat dicapai SDN 4 Bathin Solapan Kabupaten Bengkalis yaitu menguasai dasar dasar ilmu pengetahuan teknologi sebagai bekal untuk melanjutkan kesekolah yang lebih tinggi, menjadikan sekolah yang disenangi masyarakat, meraih prestasi akademik maupun non akademik minimal tingkat kecamatan dan dapat mengamalkan ajaran agama dari proses pembelajaran dan kegiatam pembiasaan. Berdirinya SDN 4 Bathin Solapan Kabupaten Bengkalis juga tidak terlepas pada tujuan khusus. Tentunya untuk mempersiapkan siswa agar mampu bersaing, dan terciptanya lulusan yang mandiri, dan beriman.

Kedua, peran manajerial kepala sekolah dalam meningkatkan mutu pendidikan Peran manajerial kepala sekolah menjadi harapan agar kepala sekolah dapat merancang atau merencanakan, mengorganisasikan, serta memonitoring proses pengelolaan sekolah dengan baik dan professional. Kepala sekolah membuat perencanaan program pendidikan sesuai dengan pelaksanaannya. Perencanaan sebuah program untuk jangka panjang maupun pendek kepala sekolah selalu mengkomunikasikan dengan pendidik dan tenaga pendidik guna untuk meminta pendapat dan bantuan dalam menyusun sebuah program tersebut. Adapun program jangka panjang sekolah SDN 4 Bathin Solapan Kabupaten Bengkalis ini menginginkan supaya sekolah menjadi salah satu sekolah favorit dalam bidang olahraga, seni, dan akademik di daerah setempat. Ketika menyusun sebuah kebijakan, kepala sekolah dibantu oleh guru yang memiliki wewenang dalam bidang kurikulum. Komite sekolah juga terlibat dalam menyusun sebuah kebijakan yang berhubungan dengan siswa dan control anggaran yang diterima oleh sekolah. Komite sekolah berperan dalam mengontrol sekolah dalam hal itu dapat dilihat dengan kehadiran komite sekolah di sekolah dan berdiskusi dengan kepala sekolah dan guru lainnya. Kepala sekolah dalam melakukan pengorganisasian sekolah. Dari hasil wawancara yang sudah saya lakukan. Kepala sekolah SDN 4 Bathin Solapan Kabupaten Bengkalis telah mengkoordinasikan, menggerakkan dan menyesuaikan sumber daya pendidikan yang ada di sekolah. Kepala sekolah berupaya mendorong sekolah agar dapat mewujudkan visi, misi, tujuan serta sasaran sekolah melalui program program yang dilakukan secara terencana dan bertahap. Kepala sekolah juga berupaya untuk memiliki dan melakukan manajemen dan kepemimpinan yang efektif guna untuk meningkatkan mutu pendidikan di SDN 4 Bathin Solapan Kabupaten Bengkalis. Peranan kepala sekolah dalam mengorganisator SDN 4 Bathin Solapan Kabupaten Bengkalis tidak sendiri adanya keterlibatan orangtua siswa dalam komite sekolah dengan melengkapi apa saja sarana yang dibutuhkan sekolah, pembagian tugas guru sesuai kemampuan guru baik di kelas maupun keterampilan yang mereka miliki, memantau pembelajaran di kelas, serta membentuk kepanitiaan ketika mengadakan lomba di sekolah.

Kepala sekolah dalam memonitoring, dari hasil wawancara yang telah saya lakukan narasumber mengatakan bahwa kepala sekolah sudah cukup baik dalam memonitoring kegiatan kegiatan sekolah. Kepala sekolah selalu melakukan kegiatan monitor semua kegiatan sekolah baik akademik maupun non akademik dengan dibantu oleh tenaga pendidik lainnya. Kepala sekolah menginginkan agar visi, misi dan tujuan sekolah tercapai. Selain itu juga kepala sekolah sedang mengupayakan untuk meningkatkan nilai ujian tahun ini agar lebih baik dari tahun sebelumnya. Adapun upaya yang dilakukan kepala sekolah yaitu kepala sekolah mengadakan jam tambahan untuk membahas mata pelajaran yang berkaitan dengan ujian. Selain itu, kepala sekolah juga melakukan monitoring terhadap guru dengan melakukan program motivasi life long education (guru harus belajar), peningkatan kesejahteraan dan memberikan kesempatan untuk berdiskusi dalam suasana yang menyenangkan, dan mendatangkan narasumber agar membimbing guru untuk melakukan pembuatan karya tulis ilmiah, mengikuti seminar, dan lainnya seperti mengikut sertakan dalam musyawarah guru mata pelajaran serta mengefektifkan tutur sebaya. Ini dilakukan agar guru dapat menjadi guru yang professional dan dapat melakukan proses belajar dengan efektif. Kualitas pendidikan di sekolah merupakan produk dari keefektifan manajerial kepala sekolah yang didukung oleh guru dan staf lainnya (Sodiqin \& Nurdin, 2016). Kepala sekolah harus memberikan pelayanan yang optimal kepada guru, sehingga guru juga akan memberikan pelayanan yang optimal kepada siswa. Pendidikan yang bermutu dihasilkan oleh kepala madrasah yang bermutu

Dalam meningkatkan mutu pendidikan di SDN 4 Bathin Solapan Kabupaten Bengkalis terdapat beberapa faktor yang mempengaruhi mutu pendidikan. Seperti kurikulum, sarana dan prasarana, serta kegiatan belajar mengajar. Pertama, kurikulum yang dilaksanakan di SDN 4 Bathin Solapan Kabupaten Bengkalis yaitu Kurikulum Tingkat Satuan Pendidikan (KTSP) yang dikeluarkan oleh Dapetemen Pendidikan Nasional sebagai kurikulum regular yang dikembangkan dengan kurikulum yang ada di SDN 4 Bathin Solapan Kabupaten Bengkalis. Dalam pelaksanaannya SDN 4 Bathin Solapan Kabupaten Bengkalis mengaami beberapa perkembangan dan perubahan dalam tatanan manajemen dan pengajaran, semuanya merupakan kea rah yang lebih baik. Oleh karena itu SDN 4 Bathin Solapan Kabupaten Bengkalis menggunakan metode pembelajaran dengan metode belajar dan bekerja ini diharapkan agar siswa dapat mengamalkan atau melaksanakan dari pengetahuan yang telah dipelajarinya di sekolah di dalam kehidupan sehari hari. siswa juga dapat belajar serta bekerja atau ptarktik menggunakan fasilitas yang ada di sekolah guna untuk memberikan keteladanan antar anak yang satu dengan yang lainnya, 
sedangkan guru menjadi fasilitator. Pembelajaran aktif dan kontekstual akan terlaksana dengan maksimal apabila didukung dengan media, metode, alat, dan bahan yang memadai (Azhari \& Kurniady, 2016; Syarifudin, 2020). Sesuai yang ada di dalam visi, misi dan tujuan sekolah., Kepemimpinan kepala sekolah mempengaruhi kondisi guru dalam melakukan aktivitasnya dalam proses pembelajaran (Player et al., 2017; Sodiah \& Nurhikmah, 2017). Sehingga rancangan yang dibuat haruslah diperhatikan dengan baik serta dibuat sesaui dengan visi dan misi.

Kedua, sarana dan prasarana. Sarana merupakan faktor yang mendukung dalam proses pendidikan, tanpa adanya sarana yang memadai maka akan sulit tercapainya mutu pendidikan yang diharapkan. Sarana yang dimiliki SDN 4 Bathin Solapan Kabupaten Bengkalis yaitu: Ruang kepala sekolah, Ruang tata usaha, Ruang guru, Mushola, Meja, Lemari, Kursi, Bangku siswa, Tv, Proyektor, Telepon, Laboraturium computer, Alat olahraga , Alat kebersihan, Camera digital. Sarana dan prasarana yang ada di SDN 4 Bathin Solapan Kabupaten Bengkalis cukup memadai. Dengan adanya sarana dan prasarana ini dapat menajdikan proses belajar mengajar menjadi lebih efektif. Selain itu juga, dengan adanya sarana dan prasarana ini sekolah dapat meningkatkan kualitas pendidikan dan dapat mengukur kualitas output dari SDN 4 Bathin Solapan Kabupaten Bengkalis. Ketiga, proses belajar mengajar Dalam proses belajar mengajar SDN 4 Bathin Solapan Kabupaten Bengkalis memiliki 26 orang guru, menurut kepala sekolah SDN 4 Bathin Solapan Kabupaten Bengkalis melalui wawancara, dari 26 orang guru $80 \%$ guru adalah ahli dalam bidangnya masing masing. Berarti sekitar 23 guru sesuai dengan kompetensinya masing masing, melihat dari data ini maka proses belajar mengajar di SDN 4 Bathin Solapan Kabupaten Bengkalis tergolong dalam pembelajaran yang efektif. Karena proses belajar mengajarnya bisa dikatakan berhasil apabila siswa yang diajarkan mendapat prestasi hasil belajar yang baik.

Upaya Kepala Sekolah Dalam Meningkatkan Mutu Pendidikan Upaya kepala sekolah SDN 4 Bathin Solapan Kabupaten Bengkalis dalam meningkatkan mutu pendidikan yyaitu dengan melakukan upaya dari berbagai bidang yaitu dengan menyusun dan menjabarkan kalender pendidikan, menyusun pembagian tugas guru dan jadwal pelajaran, mengatur program pengajarana, mengatur pelaksanaan kegiatan intrakurikuler dan ekstrakurikuler, mengatur pelaksanaan program penilaian, mengatur program perbaikan dan penilaian, mengatur mutasui siswa, mengawasi kegiatan belajar mengajar, bekerjasama dengan tata usaha bagian pendidikan dan pengajaran. Tidak hanya itu. Kepala sekolah SDN 4 Bathin Solapan Kabupaten Bengkalis juga melakukan upaya meningkatkan kualitas sumber daya manusia dengan cara meningkatkan prestasi siswa, memberikan bimbingan belajar kepada siswa dan mendisiplinkan siswa. Pelayanan pendidikan berarti semuan perangkat sekolah dari kepala sekolah, tenaga pendidikan hingga staff sekolah hendaklah benar benar memberikan pelayanan yang terbaik kepada siswa dan orangtua siswa sehingga mereka merasa puas, tidak hanya sampai putra dan putrinya lulus, tapi sejak awal mereka masuk sekolah mereka merasa aman, nyaman, terlindungi, dihargai, dan terlayani oreng perangkat sekolah.

Adanya kemampuan manajerial kepala sekolah yang baik akan dapat meningkatkan mutu pendidikan di sekolah, namun dalam menjalankan tugasnya ada beberapa hambatan yang harus di selesaikan. Kinerja guru dan kepala sekolah yang harus ditingkatkan lagi. Adapun beberapa hambatan hambatan yang dihadapi kepala sekolah dalam menjalaksanakan manajerial. Pertama, masih kurangnya komunikasi kepala sekolah dengan pendidik dan tenaga pendidik yang sudah berusia lanjut. Dalam hal ini kepala sekolah selalu melakukan diskusi atau rapat untuk membahas sesuatu agar tidak ada lagi terjadinya selisih komunikasi antar kepala sekolah dengan pendidik dan tenaga pendidik. Kedua, kurang disiplin dalam pekerjaan dan proses belajar mengajar. Dalam hal ini kepala sekolah membuat keputusan untk menegur terlebih dahulu hingga si pelanggar merasa sadar akan keslahannya, jika tidak ada perubahan maka kepala sekolah akan memberikan sanksi kepada pelanggar. Ketiga, penerapan dana BOS yang aturannya telah ditetapkan sementara kebutuhan sekolah tidak sesuai dengan aturan yang telah ditetapkan dana BOS. Untuk hal seperti ini sekiranya ada kebutuhan yang mendesak kepala sekolah melakukan rapat atau mendiskusikan dengan komite sekolah dan orangtua siswa untuk sama sama mencari jalan keluar penyelesaian masalah.

Keempat, menghadapi masukkan publik yang terkadang masukkannya harus terpenuhi oleh sekolah. Untuk permasalahan seperti ini kepala sekolah selalu melakukan filter atau penyaringan untuk apa yang telah dikemukakan oleh public apakah itu cocok atau tidak diterapkan di sekolah. Namun dengan ini kepala sekolah tidak henti hentinya melakukan upaya untuk memberikan pelayanan yang terbaik kepada pelanggan pendidikan atau siswa dan orangtua siswa. Hal ini berdampak pada kualitas pembelajaran yang hasilnya menjadi tidak optimal. Kepala sekolah sebagai manajer harus dapat menciptakan suasana sekolah yang gembira, sehingga siswa merasakan bahwa belajar bukanlah sesuatu yang dipaksakan, melainkan sesuatu yang menyenangkan. Dengan begitu para guru dan siswa akan dengan senang menjalankan tugas dan proses belajar mengajar, untuk itu kemampuan manajerial kepala sekolah sangat penting dan menjadi keharusan bagi kepala sekolah untuk dimiliki dan menjalankan tugas dan fungsinya dengan baik.

Jadi sebagai manajer kepala sekolah SDN 4 Bathin Solapan Kabupaten Bengkalis mampu menyusun program, organisasi, dan mampu menggerakkan staff dan guru. Mampu mengoptimalkan atau memanfaatkan sumber daya sekolah dengan baik untuk upaya mencapai tujuan kependidikan di sekolah tenaga pendidik sangat mempengaruhi. Sehingga dalam hal ini kepala sekolah SDN 4 Bathin Solapan selalu melakukan monitoring serta 
melakukan evaluasi kepada peserta didik dalam proses belajar mengajar. Kepala sekolah memiliki posisi yang sangat penting dalam menggerakkan manajemen sekolah agar dapat berjalan sesuai dengan tuntutan masyarakat dan perkembangan kebutuhan zaman; khususnya kemajuan ilmu pengetahuan, teknologi, budaya, dan seni (Aqmar \& Sriyono, 2018; Sulastri et al., 2017). Bersandar pada pendapat tersebut, maka kemampuan manajerial kepala sekolah merupakan salah satu faktor dominan dalam mencapai tujuan madrasah yang bermut. Berkaitan dengan tugas kepala sekolah sebagai manajer, maka mutlaklah kepala madrasah memiliki kemampuan manajerial supaya dapat menjalankan organisasi madrasah secara efektif efisien. Kemajuan madrasah tidak akan terlepas dari kemampuan manajerial yang dimiliki oleh kepala madrasah, karena pada hakikatnya manajemen merupakan proses manajerial atau pelaksanaan fungsi-fungsi manajemen di madrasah yang dilakukan oleh kepala madrasah (Oktarina \& Rahmi, 2019; Sodiqin \& Nurdin, 2016).

Hasil penelitian ini diperkuat dengan penelitian sebelumnya yang menyatakan bahwa manajerial kepala sekolah akan mempengaruhi kualitas mutu pendidikan (Masrukhin, 2018). Kepemimpinan kepala sekolah dapat meningkatkan prestasi belajar siswa, motivasi guru dan kepercayaan diri (Kastawi, 2021; Kurniawati et al., 2020; S. Liu et al., 2016). Dari hasil penelitian tersebut diperoleh bahwa manajerial kepala sekolah dalam meningkatkan mutu pendidikan yaitu untuk melakukan pengelolaan dan mendayagunakan sumber daya pendidikan yang dimiliki sekolah dengan cara bersama sama mencapai tujuan yang telah ditetapkan. peran kepala sekolah sebagai manajer dilakukan dengan menerapkan prinsip perencanaan, pengorganisasian, dan monitoring. Manajerial kepala sekolah yang baik akan menghasilkan mutu pendidikan yang baik juga yang tentunya akan mempengaruhi hasil belajar dan prestasi sekolah. Hasil penelitian ini diperoleh bahwa masih dibutuhkan sebuah program untuk meningkatkan mutu pendidikan baik berkaitan dengan pembelajaran maupun tidak.

\section{SIMPULAN}

Peran kepala sekolah sebagai manajerial yaitu untuk melakukan pengelolaan dan mendayagunakan sumber daya pendidikan yang dimiliki sekolah dengan cara bersama sama mencapai tujuan yang telah ditetapkan. peran kepala sekolah sebagai manajer dilakukan dengan menerapkan prinsip perencanaan, pengorganisasian, dan monitoring. Manajerial kepala sekolah yang baik akan menghasilkan mutu pendidikan yang baik juga yang tentunya akan mempengaruhi hasil belajar dan prestasi sekolah. Hasil penelitian ini diperoleh bahwa masih dibutuhkan sebuah program untuk meningkatkan mutu pendidikan baik berkaitan dengan pembelajaran maupun tidak.

\section{DAFTAR PUSTAKA}

Aqmar, A. Z., \& Sriyono, H. (2018). Persepsi Atas Gaya Kepemimpian Kepala Sekolah Dan Tipe Kepribadian Terhadap Kinerja Guru. Jurnal Pendidikan IPS, 1(3), 218-227.

Azhari, U. L., \& Kurniady, D. A. (2016). Manajemen Pembiayaan Pendidikan, Fasilitas Pembelajaran, Dan Mutu Sekolah. Jurnal Administrasi Pendidikan, 23(2). https://doi.org/10.17509/jap.v23i2.5631.

Cheng, A. Y. N., \& Szeto, E. (2016). Teacher leadership development and principal facilitation: Novice teachers' perspectives. Teaching and Teacher Education, 58, 140-148. https://doi.org/10.1016/j.tate.2016.05.003.

Fadhli, M. (2017). Manajemen peningkatan mutu pendidikan. Tadbir: Jurnal Studi Manajemen Pendidikan, 1(2), 215-240. https://doi.org/10.29240/jsmp.v1i2.295.

Fauzi, M. S., \& Falah, M. S. (2020). Peran Kepala Sekolah dalam Meningkatkan Mutu Pendidikan: Studi Kasus di SMAU 1 Gresik. JM-TBI: Jurnal Manajemen Dan Tarbiyatul Islam, 1(1), 54-76. http://ejournal.unhasy.ac.id/index.php/jm-tbi/article/view/1440.

Grissom, J. A., Kalogrides, D., \& Loeb, S. (2015). Using Student Test Scores to Measure Principal Performance. Educational Evaluation and Policy Analysis, 37(1), 3-28. https://doi.org/10.3102/0162373714523831.

Hastowo, A., \& Abduh, M. (2021). Analisis Kemampuan Manajerial Kepala Sekolah Dalam Implementasi Pembelajaran Daring. Scholaria: Jurnal Pendidikan Dan Kebudayaan, 11(3), 252-263. https://ejournal.uksw.edu/scholaria/article/view/4444.

Hastuti, P. M. (2017). Hubungan Kemampuan Manajerial Kepala Madrasah dan Motivasi Berprestasi Guru Terhadap Kinerja Guru Madrasah. Jurnal Ilmiah Bidang Pendidikan, 11(1), 55-62.

Juniarti, E., Ahyani, N., \& Ardiansyah, A. (2019). Pengaruh Kepemimpinan Kepala Sekolah Dan Efikasi Diri Guru Terhadap Kinerja Guru. Reslaj: Religion Education Social Laa Roiba Journal, 1(3), 193-199. https://doi.org/10.47467/reslaj.v1i2.108.

Kastawi, N. S. (2021). Kontribusi Motivasi Kerja dan Peran Kepala Sekolah Terhadap Profesionalisme Guru SMA. Jurnal Manajemen Pendidikan, 8(1), 77-93. https://ejournal.uksw.edu/kelola/article/view/4312.

Kurniady, D. A., Setiawati, L., \& Nurlatifah, S. (2018). Manajemen Pembiayaan Pendidikan Terhadap Mutu Sekolah Menengah Kejuruan. Jurnal Penelitian Pendidikan, 17(3), 263-269. https://doi.org/10.17509/jpp.v17i3.9620. 
Kurniawati, E., Arafat, Y., \& Puspita, Y. (2020). Peran Kepemimpinan Kepala Sekolah dalam Meningkatkan Mutu Pendidikan melalui Manajemen Berbasis Sekolah. Journal of Education Research, 1(2), 134-137. https://doi.org/10.37985/joe.v1i2.12.

Liu, S., Hallinger, P., \& Feng, D. (2016). Supporting the professional learning of teachers in China: Does principal leadership make a difference? Teaching and Teacher Education, 59, $79-91$. https://doi.org/10.1016/j.tate.2016.05.023.

Liu, Y., \& Werblow, J. (2019). The operation of distributed leadership and the relationship with organizational commitment and job satisfaction of principals and teachers: A multi-level model and meta-analysis using the 2013 TALIS data. International Journal of Educational Research, 96(December 2018), 41-55. https://doi.org/10.1016/j.ijer.2019.05.005.

Margareta, R., \& Ismanto, B. (2017). Strategi Perencanaan Pembiayaan Sekolah dalam Peningkatan Mutu di SMP Negeri. Jurnal Manajemen Pendidikan, 4(2), 195-204. https://doi.org/10.24246/j.jk.2017.v4.i2.p195204.

Masrukhin. (2018). Pengaruh Kemampuan Manajerial Kepala Sekolah Dan Komite Sekolah Terhadap Budaya Organisasi Dan Efektifitas Penyelenggaraan Sekolah. Edukasia: Jurnal Penelitian Pendiidkan Islam, 13(1), 105 - 126. https://doi.org/10.21043/edukasia.v13i1.3226.

Norma Puspitasari. (2015). Kemampuan Manajerial Kepala Sekolah Dalam Meningkatkan Kinerja Guru. Jurnal $\begin{array}{lllll}\text { INFORMA Politeknik Indonusa } & \text { Surakarta, }\end{array}$ http://journal.umpalangkaraya.ac.id/index.php/anterior.

Oktarina, M., \& Rahmi, A. (2019). Kompetensi Manajerial Kepala Sekolah Dalam Meningkatkan Profesional Guru. Jurnal Studi Penelitian, Riset, Dan Pengembangan Pendidikan Islam, 7(1), 1-20. http://ojs.serambimekkah.ac.id/tarbawi/article/view/1367.

Player, D., Youngs, P., Perrone, F., \& Grogan, E. (2017). How principal leadership and person-job fit are associated with teacher mobility and attrition. Teaching and Teacher Education, 67, 330-339. https://doi.org/10.1016/j.tate.2017.06.017.

Ramadoni, W., Kusmintardjo, \& Arifin, I. (2016). Kepemimpinan Kepala Sekolah Dalam Upaya Peningkatan Kinerja Guru (Studi Multi Kasus Di Paud Islam Sabilillah Dan Sdn Tanjungsari 1 Kabupaten Sidoarjo). Jurnal Pendidikan (Teori Dan Praktik), 1500-1504. https://doi.org/http://dx.doi.org/10.17977/jp.v1i8.6620.

Rismawan, E. (2015). Pengaruh supervisi kepala sekolah dan motivasi berprestasi guru terhadap kinerja mengajar guru. Jurnal Administrasi Pendidikan, 22(1), 114-132. https://doi.org/10.31227/osf.io/7azuy.

S, S., Herlambang, T., \& Cahyono, D. (2018). Dampak Motivasi, Disiplin Kerja Dan Kepemimpinan Kepala Sekolah Terhadap Kinerja Guru. Jurnal Sains Manajemen Dan Bisnis Indonesia, 8(2), 131-147. https://doi.org/10.32528/jsmbi.v8i2.1785.

Santiari. (2020). Kontribusi Kepemimpinan Kepala Sekolah, Iklim Kerja, dan Motivasi Kerja Terhadap Kinerja Guru. Jurnal Administrasi Pendidikan Indonesia, 11(1), 54-63. https://doi.org/10.23887/japi.v11i1.3149

Setiyati, S. (2016). Pengaruh Kepemimpinan Kepala Sekolah Terhadap Motivasi Kerja dan Kinerja Guru. Ilmu Pendidikan: Jurnal Kajian Teori Dan Praktik Kependidikan, 1(2), 63-70. https://doi.org/10.17977/um027v1i22016p063.

Sidiq, U., \& Choiri, M. (2019). Metode Penelitian Kualitatif di Bidang Pendidikan. CV. Nata Karya.

Sodiah, S., \& Nurhikmah, E. (2017). Etika Kerja Kepala Sekolah Dalam Meningkatkan Kinerja Guru. Tadbir : Jurnal Studi Manajemen Pendidikan, 1(2), 163. https://doi.org/10.29240/jsmp.v1i2.294.

Sodiqin, H., \& Nurdin, D. (2016). Kemampuan manajerial kepala madrasah dan kinerja mengajar guru dalam mutu pendidikan. Jurnal Administrasi Pendidikan, 23(2), 89-101. https://doi.org/10.17509/jap.v23i2.5636.

Sugiyono. (2017). Metode Penelitian Kualitatif. Bandung: Alfabeta.

Sukayana, I. W., Yudana, M., \& Hendra Divayana, D. G. (2019). Kontribusi Kepemimpinan Transformasional, Supervisi Akademik Kepala Sekolah, Kompetensi Pedagogik dan Motivasi Kerja Terhadap Kinerja Guru di SMK Kertha Wisata Denpasar. Jurnal Administrasi Pendidikan Indonesia, 10(2), 157-162. https://doi.org/10.23887/japi.v10i2.2804.

Sulastri, S., Nurkolis, N., \& Rasiman, R. (2017). Pengaruh Kepemimpinan Kepala Sekolah Dan Motivasi Kerja Terhadap Mutu Sekolah Dasar Di Kabupaten Jepara. Jurnal Manajemen Pendidikan (JMP), 5(3), $167-171$. https://doi.org/10.26877/jmp.v5i3.1984.

Sulfemi, W. B. (2020). Pengaruh Rasa Percaya Diri Dan Gaya Kepemimpinan Kepala Sekolah Terhadap Kinerja Guru. Nidhomul Haq: Jurnal Manajemen Pendidikan Islam, 5(2), 157-179. https://doi.org/10.31538/ndh.v5i2.557.

Sumarni. (2016). Kontribusi motivasi berprestasi dan kepemimpinan kepala sekolah terhadap kinerja guru SMA Negeri di Kecamatan Koto Tangah Kota Padang. Economica, 5(1), 63-68. https://doi.org/10.22202/economica.2016.v5.i1.307.

Syarifudin, A. S. (2020). Impelementasi pembelajaran daring untuk meningkatkan mutu pendidikan sebagai 
dampak diterapkannya social distancing. Jurnal Pendidikan Bahasa Dan Sastra Indonesia Metalingua, 5(1), 31-34. https://doi.org/10.21107/metalingua.v5i1.7072.

Taswir. (2014). Manajerial Kepala Sekolah Dalam Meningkatkatkan Kinerja Guru Pada Sekolah Menengah Kejuruan (Smk) Negeri 2 Sinabang Kabupaten Simeulue. Jurnal Ilmiah Didaktika, 14(2). https://doi.org/10.22373/jid.v14i2.504.

Wills, G. (2016). Principal leadership changes and their consequences for school performance in South Africa. International Journal of Educational Development, 51, 108-124. https://doi.org/10.1016/j.ijedudev.2016.08.005.

Zheng, Q., Li, L., Chen, H., \& Loeb, S. (2017). What Aspects of Principal Leadership Are Most Highly Correlated With School Outcomes in China? Educational Administration Quarterly, 53(3), 409-447. https://doi.org/10.1177/0013161X17706152. 